\title{
Entre o real e o representado: um debate na história dos animais $^{1}$
}

\author{
Between the real and the represented: a debate in \\ the history of animals
}

\section{Andréa Osório*1}

\section{Palavras-chave: \\ História; \\ Animais; \\ Agência; \\ Ciência; \\ Representação.}

\section{Keywords:}

History;

Animals;

Agency;

Science;

Representation.
Resumo: A história dos animais é um campo recente que vem sofrendo um progressivo incremento. Na primeira produção da área, o enfoque estava nas representações animais. Num segundo momento, o chamado animal "real" começou a ser incorporado às narrativas. É nesse momento que se observa a centralidade da agência animal, amparada tanto por teorias sociológicas quanto pela incorporação da etologia de viés naturalista. O ensaio faz uma revisão bibliográfica destes dois momentos, apontando para as implicações de se incluir relatos etológicos como fontes para a escrita da história, entre elas, a questão da representação nos relatos científicos e a da reiteração de uma divisão entre ciências naturais e humanas (ou sociais) e os animais como seres naturais.

\begin{abstract}
The history of animals is a recent and increasing field. Its literature used to focus on animal representation, but in the later works the so-called "real animal" started to appear. At this second moment, animal agency gains centrality through the mobilization of sociological theories as much as ethological literature, especially naturalistic works. The present essay reviews this two periods aiming to bring light to the limits and consequences of using ethological material as a source to write history. Namely that they also present a representation of the objects studied and that this kind of source may enforce the division between natural and social sciences and the animal as a natural being.
\end{abstract}

\footnotetext{
${ }^{1}$ Recebido em 12/03/2015 e aceito para publicação em 18/08/2015.

*1 Doutora em Antropologia, professora no Instituto de Ciências da Sociedade, na Universidade Federal Fluminense. Email: andrea.osorio@ig.com.br.
} 


\section{Introdução}

A história dos animais é um campo recente que teve início na segunda metade do século XX e tem crescido desde então. Os paradigmas da área estão informados pelos debates do próprio campo historiográfico, mas também pelos animal studies (KRUSE, 2002; MULLIN, 2002; RITVO, 2002), área multidisciplinar que teria emergido na década de 1970 (BIRKE, 2002), em meio a movimentos de proteção animal que, não obstante, remontam ao século XIX (RITVO, 2002).

Alguns autores (BAKER, 1993; FUDGE, 2002; MULLIN, 2002) identificaram dois paradigmas correntes nos animal studies: um que pode ser chamado de materialista (MULLIN, 2002), em busca do animal real em suas relações com os humanos (BAKER, 1993); e outro semiótico (MULLIN, 2002), pós-estruturalista (FUDGE, 2002) ou simbólico, em busca de representações acerca do animal. A diferença parece residir, essencialmente, no tipo de abordagem. Autoras como Mullin (2002) e Fudge (2002) tendem a se queixar de uma proeminência de estudos de aspecto simbólico, nos quais as representações sobre os animais são preponderantes, e exortam os leitores a estudos que esclareçam as relações concretas que humanos e animais travam. Esse animal real estaria sendo incluído paulatinamente nas análises históricas na última década (FUDGE, 2014).

A dicotomia entre animal real e animal representado é uma variação da tensão entre natureza e cultura. Se alocados no universo natural, os animais não podem ter uma história (PREMACK \& PREMACK, 1994), mas quando em contato com humanos, o registro humano dos animais se torna fonte de uma história dos animais. Não se trata, portanto, de uma história natural, mas de uma história das relações humano-animal, e vice-versa (INGOLD, 2000).

$\mathrm{Na}$ produção mais contemporânea, essa dicotomia tem sido explorada a partir da noção de agência animal. A busca de uma agência animal, segundo Despret (2013), está alinhada tanto a pesquisas etológicas que tentam alcançar o ponto de vista animal quanto a uma agenda política que "credita os animais com interesses, vontades, preferências e intenções que devem ser levadas em conta" (DESPRET, 2013, p. 30). O animal com um ponto de vista, uma perspectiva e uma agência é, assim, tornado um sujeito (DESPRET, 2013). A etologia se torna concomitantemente fonte e objeto de análise para se compreender os animais do passado (FUDGE, 2014) e os animais em geral, em suas relações com seres humanos e com outros animais (DESPRET, 2013). A superação da dicotomia tenta duas subversões: por um lado, abandonar a separação entre natureza e cultura e, por outro, a visão mecanomórfica dos animais, diminuindo as críticas quanto a uma visão antropomórfica dos mesmos (CRIST, 1999).

No presente ensaio pretendo apresentar as linhas gerais desse debate, a partir de uma revisão bibliográfica, com maior ênfase para a dicotomia apresentada no título. As obras selecionadas compreendem alguns dos principais autores em história dos animais em língua inglesa, especialmente aqueles que passaram a incluir o problema da agência animal. Algumas obras sobre animais de autores menos conhecidos ou citados proporcionam um 
contraponto que é explorado no ensaio. Autores francófonos também foram incluídos, embora em menor escala. Nesse sentido, apenas segue-se o ritmo da produção anglófona, que tem popularizado a percepção dos animais na história tanto quanto colocado os questionamentos que deram origem a este ensaio. Fudge $(2002 ; 2014)$ torna-se a guia privilegiada dessa viagem, pois estabelece a noção de dois momentos na produção da área.

Chamo a atenção, contudo, para algumas consequências de se incluir fontes etológicas em pesquisas historiográficas. A busca por materialidade nessas fontes desloca a solução encontrada para a velha tensão entre sujeito e objeto. Dependendo da fonte, conforme análise de Crist (1999), a descrição científica apontará animais cujas condutas e comportamentos são explicados e descritos em termos diferentes. Em outras palavras, a etologia não apresenta um conteúdo neutro que embase a materialidade do animal e é, portanto, uma fonte escrita como outras, cujo bias deve ser levado em consideração.

A maior parte da literatura de história dos animais está em língua estrangeira e percebe-se uma escassez de produção nacional específica sobre história dos animais. Nesse sentido, a lacuna que o(a) leitor(a) sentirá acerca dos animais brasileiros é apenas o reflexo desse vazio. Em que pese uma produção recente em animal studies no Brasil, sobretudo em antropologia e em direito, apenas para mencionar campos das ciências humanas, na história ${ }^{2}$, como disciplina acadêmica, as obras ainda estão por vir.

\section{Não há uma história dos animais}

Para Noske (1993), enquanto se apresenta os humanos como fazedores de sua própria história, os animais são apresentados como tendo apenas uma história natural, feita para eles - pelos cientistas, diria Latour (1994) - e que se baseia na evolução das espécies. Ancorados no polo natureza da divisão moderna entre natureza e cultura (LATOUR, 1994), os animais não teriam

2 No presente ensaio, optei por não distinguir, na grafia, a história como disciplina acadêmica da história como uma teoria da mudança, conforme os debates lévi-straussianos sobre a historicidade e a história dos historiadores (GOLDMAN, 1999), porque entendo que a escrita da história, para parafrasear um título famoso, embora possa representar o mundo narrado de formas distintas, está preocupada com a mudança, a agência, o tempo e o espaço, ou seja, com os elementos constituintes da historicidade. No presente ensaio, adicionar essa dicotomia às muitas já apresentadas apenas reproduziria, a meu ver, um dilema entre os fatos e seu estudo científico, como analisa Latour (200a; 2001). Excluo aqui, também propositalmente, as questões dos capítulos finais d'O Pensamento Selvagem (LÉVI-STRAUSS, 2008) sobre o sentido da história (ou filosofia da história, que compõem, com a historicidade e o estudo da história, algumas das preocupações do mestre francês), porque esse debate não se apresenta na literatura sobre história dos animais. Como afirma Goldman (1999), "nesse sentido, tanto a 'história dos historiadores' quanto a 'filosofia da história' fazem parte constitutiva de nossa forma particular de historicidade, ou, ao menos, daquela dominante no Ocidente há muitos séculos" (GOLDMAN, 1999). Aproveito para esclarecer que meu uso pontual das noções lévi-straussianas da história se deve a um recorte que privilegia a literatura sobre história dos animais. Creio que há interseções possíveis e interessantes a serem pensadas, a partir daqui, entre a noção de que podemos escrever a história dos animais e os debates estruturalistas sobre a história. Também deixo para uma outra oportunidade uma reflexão mais detida sobre a história na obra de Bruno Latour, um autor mais presente aqui do que Lévi-Strauss.

Caderno Eletrônico de Ciências Sociais, Vitória, v. 3, n. 1, pp. 75-94. 
cultura, nem história, a não ser como objetos que se ligam a humanos e ingressam nas redes de coletivos compostos por humanos e não-humanos (LATOUR, 1994).

Assim, por exemplo, para Premack \& Premack (1994), os animais não possuem nem história nem cultura, mas é possível escrever a história de como os humanos trataram os animais. Sua definição de história é a de "uma sequência de mudanças pelas quais uma espécie passa enquanto se mantém biologicamente estável" (PREMACK \& PREMACK, 1994, p. 350).

\begin{abstract}
"A história, contudo, não é um produto automático do cérebro humano nem um inevitável concomitante da cultura. [...] Para ter história um grupo precisa atuar sobre o mundo para modificá-lo - e, ao fazê-lo, modificar a si mesmo" (PREMACK \& PREMACK, 1994, p. 351).
\end{abstract}

Há muitas questões em aberto nas passagens acima, especialmente sobre o quanto um animal pode modificar o mundo e o quanto pode modificar a si mesmo, mantendo-se, ao mesmo tempo, biologicamente estável. Se nos perguntarmos o quanto o ser humano se manteve biologicamente estável ao longo de sua história e existência, a primeira tentativa de resposta teria que tentar conceituar "estável", para dizer o mínimo. Percebe-se, assim, que a premissa de uma estabilidade biológica é, em si, problemática. Com relação aos animais domésticos, cuja multiplicidade de raças criadas por humanos é enorme, "estável" também é um termo a ser definido. A tendência de um tipo de ciência da natureza3 é a de enxergar o animal como estável e, como consequência, incapaz de modificar a si mesmo (CRIST, 1999), o que dirá o mundo.

Por outro lado, não sendo "produto do cérebro", a história sai do âmbito da natureza e recai no da sociedade. Mas, se a história não é um "concomitante da cultura", então nem todas as sociedades humanas produzem história e aqui ouve-se os ecos das noções lévi-straussianas de sociedades quentes e frias (LÉVI-STRAUSS, 2008). Segundo Lévi-Strauss (2008), sociedades sem história são "frias", enquanto sociedades com história são "quentes". Nestas, têm-se um pensamento domesticado, ao passo que naquelas um pensamento selvagem, termos que coincidentemente são utilizados para classificar os animais. O cerne do debate sobre a história, para este autor, reside não num uso instrumental desta pela antropologia, mas na ideia de que a própria história é um produto de uma determinada estrutura social e é uma forma de pensamento4.

Sociedades quentes interiorizam o movimento histórico e fazem dele seu motor de desenvolvimento, construindo uma noção de continuidade e de tempo linear. Sociedades frias anulariam os efeitos dos fatores históricos, observando o passado como um modelo intemporal. Utilizariam um tempo cíclico, de ciclos de repetição, observado tanto na natureza das mudanças sazonais, como, por exemplo, nos rituais. Estes ciclos não causam mudanças na estrutura social.

3 Possivelmente também uma tendência encontrada nas ciências humanas, por transferência de um campo ao outro.

4 Se os animais não "pensam", não podem produzir história. Essa afirmação será posta em cheque pela produção recente em história dos animais. 
Estas sociedades mantêm o estado primeiro de seu desenvolvimento, estado mítico, prevenindo ou rompendo a força de mudança dos acontecimentos. Em Lévi-Strauss (2008), portanto, sociedades frias não estão imunes às mudanças, mas tentam se defender dessas mudanças. Segundo o autor, a história não é sinônimo da humanidade, mas um método "indispensável para inventariar a integralidade dos elementos de uma estrutura qualquer, humana ou nãohumana" (LÉVI-STRAUSS, 2008, p. 290-1). Como método indispensável, podese sugerir seu uso na compreensão das relações estruturais entre humanos e animais.

Em Premack \& Premack (1994), é como se os animais que não estão em contato com os humanos não possuíssem história, e os que estão possuíssem a história que a cultura dos humanos em contato permitisse. Em resumo, num mundo humano em que não houvesse história, os animais deste mundo também não a teriam. A história dos animais se torna um epifenômeno da história humana. Uma história natural desenvolveria as mudanças naturais pelas quais passam os animais, estendendo a noção de uma mudança no tempo linear da sociedade para a natureza, ainda apartadas. Aqui, não se trata tanto das mudanças que os sujeitos históricos imprimem no mundo, mas que este imprime sobre eles. Em Premack \& Premack (1994), a separação entre uma natureza cujas mudanças são vistas como 'naturais' (uma afirmação redundante) e uma humanidade que pode criar ou não história aloca os animais como objetos passivos da história humana. Estas visões, contudo, tem sido progressivamente abandonadas.

\section{Há uma história dos animais}

Para Ingold (2000), se há uma história das relações dos humanos com os animais, também há uma história das relações dos animais com os humanos. Mas, concordando com o paradigma da área, essa história seria narrada por humanos. Para Ritvo (2002), analisar os animais na história não é novidade, porém nas últimas décadas do século $X X$ a atitude dos historiadores teria mudado. As relações humano-animais têm atraído maior atenção desde então devido ao crescimento de movimentos de proteção animal. Segundo Fudge (2002), é impossível não relacionar o emergente campo da história dos animais com os debates sobre direitos dos animais e bem-estar animal. 0 desenvolvimento de histórias de grupos minoritários, como a classe operária e as mulheres, parece ser um precedente para a inclusão dos animais como objeto de pesquisa historiográfica (FUDGE, 2002; HRIBAL, 2007). Contudo, sua inclusão também é devedora dos debates acerca da natureza e do meio ambiente.

Fudge (2002) aponta alguns problemas metodológicos para um projeto de história dos animais. A autora indica que, como os animais não produzem documentos nem tampouco apresentam linguagem, uma pesquisa sobre eles depende necessariamente de material humano. Assim, a história dos animais é, na verdade, "a história das atitudes humanas para com os animais" (FUDGE, 2002, p. 6). Da forma como tem sido escrita, a história dos animais mostra aspectos da história humana e, segundo a autora, pode contribuir para reflexões sobre a constituição da humanidade em oposição à animalidade. 
Além da polarização antitética entre humano e animal, na qual este é definido por uma lacuna em comparação ao que aquele fabrica, há também uma antítese entre natureza e sociedade e entre história e ciências naturais. Nos termos de Latour (1994), todo o trabalho científico, levado a cabo por humanos em contextos espaço-temporais dados, pelo qual a natureza "fala", desaparece. Os animais não produzem documentos, mas os cientistas naturais produzem fatos sobre os animais ao mesmo tempo em que omitem sua participação na produção desses mesmos fatos. Assim, se uma pesquisa histórica demanda material humano, resta-nos perguntar qual pesquisa não demanda.

A separação utilizada por Fudge (2002) pressupõe que os animais podem falar com os cientistas naturais, mas não com os historiadores, e que alguns humanos devem, então, falar por eles. Mas, como aponta Latour $(1994 ;$ 2001), não falam sempre? A tensão, portanto, emerge com a dificuldade de fazer a história dos não-humanos, que não são o objeto privilegiado da história como disciplina que pensa a sociedade, e não a natureza, embora subcampos da história venham produzindo reflexões sobre a relação entre sociedade e natureza.

Para resolver a tensão, a natureza é apagada e a história retorna à sociedade e suas representações. O campo da história dos animais é disposto por Fudge (2002) como uma subárea da história das ideias e uma vertente pósestruturalista na qual os documentos possuem a centralidade narrativa e o animal real desaparece em meio a discursos e representações. Nesse sentido, a história dos animais seguiria os dilemas desenhados no debate entre empiricismo e pós-estruturalismo no próprio campo da história, a saber, segundo a autora, entre o acesso objetivo do passado através de documentos e a ideia de que a história é construída, não acessada, por meio de documentos que são representações. Se a história dos animais é acerca das representações humanas, então ela estaria localizada na tradição pós-estruturalista.

Eivada pela ideia de reconciliar animal real e animal representado, Fudge (2002) urge os historiadores dos animais a analisarem os usos que deles fazem os humanos a partir de um paradigma explícito de domínio humano sobre a natureza, que será revertido em seu segundo balanço sobre o tema (FUDGE, 2014), no qual inclui o problema da agência animal. Essa reviravolta indica como o campo tem sofrido modificações em seu paradigma inicial. Esses pontos serão tratados adiante.

Fudge (2002) propõe que a produção em história dos animais seja classificada a partir de três categorias que podem emergir misturadas em certas obras: história intelectual, história humanitária $\left(\right.$ humane $\left.^{5}\right)$ e história holística. A história intelectual tenta descortinar as percepções sobre os animais e a natureza numa determinada época. A história humanitária enfoca a materialidade do animal, investindo na relação vivida entre humanos e animais. Nesta categoria, os animais seriam capazes, através de seus porta-vozes

5 Humane é o termo que muitas associações anglófonas de defesa dos animais utilizaram no século XIX e remete à classificação da autora a estudos sobre o desenvolvimento de direitos dos animais e movimentos sociais de proteção animal. 
humanos $^{6}$ (LATOUR, 2000a), de produzir mudanças sociais. Na história holística, a representação acerca do animal oferece um caminho para repensar a cultura de forma a desenhar um novo quadro sobre o passado, incluindo as relações entre humanos. A importância do campo não está atrelada apenas à existência animal, mas à existência humana e ao esclarecimento de situações de alteridade nas quais o Outro é um animal, física ou metaforicamente.

Como exemplo de histórica intelectual, Fudge (2002) aponta o conhecido O Homem e o Mundo Natural, de Keith Thomas (1988), que busca as representações inglesas da natureza entre 1500 e 1800. Na segunda categoria, a autora inclui Animal Rights, de Hilda Kean (1998), um levantamento da produção de legislação, organizações e mobilizações que produziram a ideia de direitos dos animais na Inglaterra a partir do século XIX. Na terceira classificação, Fudge (2002) dispõe The Animal Estate, de Harriet Ritvo (1987), uma compilação de seis estudos sobre a relação de ingleses do século XIX e animais no âmbito da caça, do entretenimento, dos concursos de gado, dos concursos de cães, dos direitos dos animais e das preocupações com a epidemia de raiva. Segundo Fudge (2002), é um estudo sobre atitudes para com animais e sobre os próprios animais que, não obstante, se concentra em estratégias retóricas mais do que em animais reais.

O antropocentrismo dessas análises, contudo, chama a atenção da autora. Segundo ela, embora seja antropocêntrica, uma história dos animais pode contribuir contrariamente ao antropocentrismo se for anti-humanista (ou pós-humanista), ou seja, se questionar a absoluta separação das espécies.

\section{Representações animais na história}

No campo da história no Brasil, a tese de doutorado de Aprobato Filho (2006) e o artigo de Duarte (2013) parecem solitários como exemplares de uma história dos animais, ao contrário do que se observa no mundo anglófono. Duarte (2013) publicou o único capítulo referente ao Brasil em Centering Animals in Latin American History (FEW \& TORTORICI, 2013). Numa reflexão que enfoca os pássaros da fauna nativa brasileira, a autora perpassa as práticas de caça, a legislação protetiva, a ação de cientistas naturais em prol desses animais e as representações que algumas espécies passam a ensejar em contextos político-ideológicos marcados. Há menos sobre os animais reais na análise do que sobre suas representações, embora o artigo enfoque questões relacionadas aos cientistas e à política entre o fim do século XIX e a primeira metade do XX.

Em um interessante trabalho sobre relações humano-animais na cidade de São Paulo entre o final do século XIX e o início do XX, Aprobato Filho (2006) indica como o processo de modernização da cidade primou, paulatinamente, pelo extermínio e isolamento de certas espécies. Assim, o transporte de tração animal foi progressivamente trocado por locomotivas a vapor, bondes elétricos

6 "O porta-voz é alguém que fala em lugar do que não fala" (LATOUR, 2000a, p.119). O que não fala não é necessariamente uma coisa, mas pode ser uma pessoa. No laboratório, os cientistas falam por seus objetos de estudo. O porta-voz representa um actante, isto é, fala por ele. 
e automotores. As tropas de mula e os carros de boi seriam vistos, neste contexto de modernização, como elementos do passado colonial que se desejava extirpar. Muito se reclamava, nesse sentido, dos parasitas e insetos que acompanhavam tais animais, que pareciam encarnar, especialmente, as ideias de atraso, pasmaceira e imundície. Não obstante, o maior decréscimo no número de animais de tração (bois, cavalos, asnos e mulas) se deu, segundo o autor, no estado de São Paulo, entre as décadas de 1930 e 1940. É uma obra que utiliza os animais como argumento para observar mudanças na sociedade mais ampla, e na qual o animal real nunca emerge, mas se busca as representações da época sobre ele.

Certamente o brasileiro não está sozinho nessa opção metodológica. O famoso artigo de Darnton (1986), Os trabalhadores se revoltam: o grande massacre de gatos na Rua Saint-Séverin, é um marco dos animais nas narrativas históricas como argumento para se acessar as mentalidades do período analisado, tomando como ponto de vista não a vida real dos animais, mas a vida dos rapazes de uma tipografia. Darnton (1986) trata de um episódio ocorrido na França no início do século XVIII. Os trabalhadores de uma corporação de tipógrafos se revoltam simbolicamente contra os patrões através de uma matança de gatos. Embora centrado na estrutura hierarquizada da época e se baseando na autobiografia de um dos tipógrafos participantes no dito massacre, Darnton (1986) não apenas faz a história das pessoas comuns como indica o valor do simbólico nas relações sociais. O massacre teve múltiplas razões, que podem ser resumidas a alguns fatores: o tipo de organização (inclusive ritual) da corporação dos tipógrafos; os maus-tratos, assim compreendidos, infligidos aos neófitos; a competição entre tipografias e o resultante desemprego; a cultura popular francesa e suas concepções sobrenaturais acerca dos gatos. O objetivo, portanto, não era acessar o animal real, nem mesmo os animais representados, mas as pessoas comuns.

$\mathrm{Na}$ história dos animais em língua inglesa, The Old Brown Dog, de Coral Lansbury (1985) é mais uma obra em que o animal real desaparece, tanto da narrativa histórica quanto da perspectiva dos atores analisados. A obra descreve o impacto da segunda vivissecção de um cachorro na escola de medicina, descrita e publicada na Inglaterra eduardiana, e que se torna o mote de uma série de eventos que envolvem cientistas, políticos, feministas, operários e estudantes de medicina. Os animais reais nunca aparecem na narrativa e todo o cenário é humano e de interesse nas ações humanas e mentalidades da época.

\section{O animal real}

Buffon, ao criticar uma obra de história natural sobre os galos e os bois, indica que histórias e fábulas preenchem as páginas, deixando os próprios galos e bois reais de fora (DELORT, 1984). Tão longe quanto o século XVIII, portanto, a dicotomia entre uma história do animal real e uma história das representações animais emerge. Encontrar o animal real nas obras elencadas até aqui às vezes demanda uma lupa e outras um microscópio. Mesmo quando animais concretos ingressam nas narrativas, como é o caso de The Animal Estate (RITVO, 1987), o foco está nas pessoas. 
Alguns historiadores, contudo, fizeram experiências na busca desse animal real. Delort (1984) é um deles. Em seu Les animaux ont une histoire (DELORT, 1984), e seguindo os conselhos de Buffon, o autor não apenas afirma a existência de uma história dos animais, mas uma história dos animais sem os homens, ocupando a contramão da produção da área. A interseção entre a evolução das espécies, as relações humano-animais e pesquisas que o autor classifica de zoológicas são, segundo ele, uma tradição antiga. Operando numa estrita separação entre natureza e cultura, Delort (1984) busca na zoologia a inspiração de sua empreitada, chamando de zoohistória o campo no qual opera: de um lado, o contexto humano e a história da zoologia, de outro, o contexto natural, a evolução e o desaparecimento das espécies. Na prática, contudo, o humano permeia a narrativa em função da domesticação e de outras atividades humanas que envolvem animais,

Outras duas obras são ilustrativas. Em Animals in the service of man, Hyams (1972) faz a história da domesticação de alguns animais, entre eles cavalos, galinhas, gatos, cabras, ovelhas, cachorros, camelos, elefantes e peixes. Embora a obra tenha referências às representações de animais em sociedades dadas, elas não são o foco prioritário.

Crosby (2011) e seu Imperialismo ecológico, por sua vez, emerge como uma espécie de história ecológica da expansão europeia entre os anos 900 e 1900, que inclui ecologias locais e a adaptabilidade da fauna e da flora de exploração agrícola europeias a outros continentes. Embora o foco não esteja exclusivamente nos animais, aprende-se certos aspectos sobre sua existência concreta. Representações, contudo, são matéria escassa.

Essas obras, contudo, não expressam a produção mais recente. Nela, o conselho de Noske (1993, p.185) de dar atenção a "como as coisas são vistas [look], cheiram [smell], são sentidas [feel], provadas [taste] ou ouvidas [sound] pelos animais envolvidos" parece ter levado historiadores ao encontro de pesquisas etológicas. Nesse sentido, Fudge (2014) cita obras como The lost wolves of Japan, de Brett L. Walker (2005) e Entertaining elephants, de Susan Nance (2013), entre outras. O que justifica essa opção é uma busca pelo significado das ações animais, de forma que o seu comportamento, analisado e descrito por etólogos, seja uma fonte para a compreensão histórica das relações humano-animais.

Apesar de tudo, a tensão entre um animal real e um animal representado se mantém porque deriva, na verdade, de uma separação entre natureza e sociedade que perpassa nossa compreensão de fazer ciência (LATOUR, 1994), incluindo-se aí nossa compreensão de como fazer história. A resolução dessa tensão não é tão simples quanto incorporar o animal real nas análises semióticas, posto que os dois paradigmas não estão em conflito apenas no campo científico, mas estruturam nossos modos de relação com a sociedade e com a natureza. É necessário, portanto, não uma simples junção, mas um paradigma que não separe natureza e sociedade para que a tensão se dilua.

\section{Agência animal}

Num segundo levantamento sobre a produção em história dos animais, Fudge (2014) atualiza sua análise anterior (FUDGE, 2002) apontando para o 
crescimento da área e a ênfase recente na noção de agência, bem como em questões metodológicas específicas. Segundo a autora, obras publicadas desde o seu estado da arte anterior passaram a incluir não apenas o animal real, mas fontes etológicas que esclareçam como as espécies estudadas provavelmente agiram num tempo histórico passado. Aqui, novamente, a tensão entre um animal real e um animal representado emerge como uma tensão entre natureza e cultura. A busca do real encaminha certos pesquisadores a fontes que poderíamos considerar a-históricas, no sentido de uma natureza ou uma ciência da natureza que apresentam comportamentos animais imutáveis. Mas esse não é o caminho tomado por essa nova proposta.

A produção mais recente elencada por Fudge (2014) aponta para uma historicidade dos próprios animais, desvinculando a história do domínio da razão e, concomitantemente, da humanidade. Ao fundo desse deslocamento, ouve-se reiteradamente a ideia marxiana de que os homens não fazem sua história como querem (MARX, 2011) - portanto, racionalidade e intencionalidade deixam de ser requisitos da historicidade. O deslocamento permite, embora incoerente à teoria marxiana da história, a inclusão dos não-humanos. Fudge (2014) indica que, ainda assim, trata-se de uma história humanista, onde a centralidade humana é inegável, mas que permite uma visão dos animais como atores e agentes. Percebe-se um reconhecimento de que o mundo humano não é feito apenas de humanos e que, entre os não-humanos, os animais apresentam um impacto específico na constituição não apenas da noção de humanidade (INGOLD, 2000), mas nas vidas humanas. Assim, tanto quanto são representados, os animais convivem concretamente com os humanos constituindo seu mundo e a si próprios com eles.

Um terceiro elemento que emerge, conjuntamente aos anteriores, é uma fenomenologia dos comportamentos animais. O limite dessa fenomenologia, contudo, é a impossibilidade de registro da experiência animal do mundo, seu ponto de vista ou perspectiva, embora essa experiência não seja negada. "Pensar como um animal" seria uma consequência de se relacionar com ele, mesmo de formas dominadoras, embora a perspectiva humana permeie essas suposições sobre a mente animal. Não se pode, aponta Fudge (2014), experimentar o mundo como um animal, embora devamos recorrentemente nos perguntar como um animal o está fazendo. Qualquer tentativa de se colocar em seu lugar geraria um viés antropomórfico. Aqui, também, a etologia é uma ferramenta para os animal studies. O comportamento animal passa a ser visto, quando na interação com humanos, como tendo historicidade, o que permite à autora sugerir um engajamento subjetivo dos animais no mundo.

Numa análise crítica dos conceitos de agência e perspectiva, Despret (2013) indica que "agência" emerge na década de 1970 como crítica ao estruturalismo e que era classicamente compreendida como intencional, racional e premeditada. "Perspectiva", por sua vez, repousa na ideia de subjetividade. O seu uso no contexto de relações humano-animal demandou, portanto, uma recategorização dessas noções, de modo que um ator racional autônomo desse lugar a seres distintos cujas capacidades cognitivas são muito variadas.

Para uma reflexão da agência animal, Despret (2013) toma a ideia deleuziana de agencement como ponto focal: 


\begin{abstract}
"um agencement é uma relação de forças que faz alguns seres capazes de fazer outros seres capazes, de uma forma plurivocal, de modo que o agencement resista ser desmembrado, resista distribuições com um corte claro. [...] Agência é o produto desse agencement; não há agência sem agencement. Em outras palavras, a agência de um ser testemunha a existência de um agencement. [...] Agência parece muito intimamente ligada a um mundo de experiências sensórias. [...] A experiência sensória acontece onde organismos vivos tocam um ao outro, afetam e são afetados um pelo outro. Nós reconhecemos uma experiência sensória como a experiência concreta na qual cada um dos atores-a-ser [becoming-actors] efetuam em outros o poder de ser afetado. Uma experiência sensória é um fluxo de forças. Essas são as forças que sintonizam, agenciam [agence] (ao invés de congregarem) o agencement, e essas são as forças que desempenham e articulam a agência. Força deve ser compreendida em termos de seu poder de afetar outras forças com as quais está relacionada e de ser afetada por outras forças, por sua vez" (DESPRET, 2013, p. 38).
\end{abstract}

De forma sucinta, não há agência unilateral e a agência não depende de um aparato racional, mas de uma experiência mediada por um corpo. "Agência, portanto, aparece claramente como a capacidade de fazer outros fazerem coisas, mas de incita-los, inspira-los ou requisita-los a fazerem coisas" (DESPRET, 2013, p. 40). A agência é relacional e cria efeitos entre as partes, não como uma relação entre ativo e passivo, mas num fluxo que dá ao outro a chance de fazer também. Para a autora, agência não envolve independência mas, ao contrário, dependência de outros seres. Ela nomeia os agentes nesse fluxo de "agentes-companheiros". Toda agência se torna, assim, "interagência".

Segundo Fudge (2014), se o comportamento animal é tomado como significativo, então uma consequência de se analisar o animal real é a visibilidade de sua capacidade de agência. De objetos, os animais se tornam sujeitos com os quais se negociar. A ideia de negociação emerge em análises nas quais a conduta cooperativa animal só se torna visível na sua recusa, identificada então como resistência (DESPRET, 2013). Nessa invisibilidade, os animais se tornam "agentes secretos", mas em sua recusa, resistência e negociação a agência animal se torna mais visível (DESPRET, 2013).

Segundo Hribal (2007), a produção em história dos animais está perpassada pela influência da história social e pela noção de que minorias subrepresentadas historicamente devem ser trazidas à luz. No entanto, alerta o autor, dar visibilidade a estes grupos pode ser feito a partir deles mesmos ou a partir de categorias e representações sobre eles. Nesse sentido, o autor propõe que classe e agência sejam categorias analíticas metodologicamente empregadas na tarefa de fazer uma história dos animais a partir deles próprios. Agência é definida como a habilidade que um grupo minoritário teria de influenciar ou dirigir sua própria vida. Ainda que sob forte dominação e opressão, alguma margem de negociação e resistência apresentar-se-ia. Classe é definida como uma relação, horizontal ou vertical, entre seres reais concretos. A combinação de classe e agência permitiria ao historiador perceber como o grupo ou sujeito em questão molda o processo histórico. Estar-se-ia, buscando, portanto, um animal real, capaz de agir, resistir, negociar e fazer história. 
É na interação com os humanos que os animais fazem sua história, adaptando-se às circunstâncias, como qualquer outra espécie (FUDGE, 2014). A agência, contudo, não emerge apenas no que os animais fazem, mas em registros sobre o que eles deixam de fazer: animais selvagens que não atacam e animais domésticos que se recusam a trabalhar são exemplos não apenas de condutas de animais reais, mas concomitantemente de representações sobre os animais (FUDGE, 2014). A inserção dos animais reais na história dos animais não afasta, portanto, as representações, nem parece ser esse o objetivo.

Fudge (2014) sugere que se escreva uma itstory ${ }^{7}$, ou seja, uma história das coisas no sentido de uma história dos não-humanos. A história se afasta, portanto, de sua zona de conforto e passa a compreender o mundo humano como permeado pela natureza, por animais e outras "coisas". Percebe-se, assim, a inclusão de preocupações mais amplas do que os próprios animais, como as questões ecológicas e teorias sobre não-humanos.

Se acessar os animais a partir deles mesmos não significa que eles falarão português e escreverão sua própria história em microcomputadores, significa que podem falar por outros meios e que sua história não está separada da história da humanidade, podendo, portanto, ser escrita em conjunto. Como Latour (1994) indica sobre a história dos não-humanos, escrevê-la é também falar da sociedade que os produziu. Não se trata, assim, de retornar a uma história natural, mas de romper a separação entre humanos-sujeitos e animaisobjetos, eu sugeriria, para se falar da relação entre as espécies a partir dos coletivos latourianos.

\begin{abstract}
"No mundo da revolução copernicana, onde tudo deveria poder ser colocado entre os dois pólos da natureza e da sociedade, a história no fundo não valia nada. Tudo o que se fazia era descobrir a natureza ou desdobrar a sociedade ou aplicar uma sobre a outra. Os fenômenos nada mais eram do que o encontro de elementos que sempre estavam presentes anteriormente. Havia uma história contingente, mas apenas para os humanos, desvinculada da necessidade das coisas naturais" (LATOUR, 1994, p. 80).
\end{abstract}

A descoberta da natureza não é a fabricação de um fato científico no laboratório, diz Latour $(1994 ; 2001)$, embora se apresente como tal. Como ato de fabricação, o fato perderia seu caráter natural para se tornar humano. Mas, como o autor crê na realidade concreta acessada nos laboratórios, esses fatos se tornam o estopim de sua reflexão sobre coletivos, naturezas-culturas e quase-objetos. Sendo naturais, eles não teriam uma história. Tomando-os como parte de naturezas-culturas, eles passam a ter história. Diz o autor:

"A partir do momento em que atribuímos historicidade a todos os atores, a fim de acolher a proliferação dos quase-objetos, a natureza e a sociedade tornam-se tão inexistentes quanto o Oeste e o Leste" (LATOUR, 1994, p. 84).

7 Em alusão à proposta feminista de uma her-story no lugar de uma his-story. 
Para propor a história dos animais como uma história dos coletivos de humanos e não-humanos é necessário tomar os animais como esses híbridos de natureza-cultura. Não existindo uma natureza apartada da cultura, nem uma cultura apartada da natureza, tanto animais domésticos quanto animais selvagens podem ter uma história que, não obstante, inclui os seres humanos. Não se trata nem de antropocentrismo, nem de zoocentrismo, mas de uma narrativa sobre as inter-relações (ou interagências) entre humanos e outras espécies animais nas quais estas também sejam agentes.

Apesar da sugestão de tratamento das relações humano-animais como coletivos latourianos (1994), é necessário efetuar uma ressalva metodológica trazida à tona por Fudge (2014): no tratamento do passado convém não impor modos de pensar que não estão ali presentes. Não se propõe, portanto, obliterar divisões entre natureza e cultura que estejam presentes em determinados contextos, ou suscitar divisões onde elas parecem não existir, mas tomar a noção de coletivo (LATOUR, 1994) como uma ferramenta para observar o animal real e a sua representação inextricavelmente ligados, em contextos passados ou atuais. Se Latour (1994) estiver certo e nunca tivermos sido modernos, então não se trata de uma tarefa tão difícil.

\section{Etologia e representações científicas}

Um dos problemas da inclusão de material etológico na história dos animais em busca do animal real é que a ciência também produz narrativas e a realidade de um animal pode se esvair em outras representações. Corre-se o risco, ainda, de formular um Frankenstein, juntando representações de humanos específicos em interações com animais específicos, e talvez espécies localizadas, com representações científicas produzidas em outros contextos. 0 primeiro aspecto será tratado ao longo dessa seção. O segundo é exemplificado pelo medievalista francês Pastoureau (2010), quando acusa certas análises de anacronismo por não utilizarem as classificações zoológicas do período estudado, mas da ciência moderna.

Crist (1999), numa análise acerca da escrita científica e sua descrição dos animais, permite um quadro comparativo das representações científicas dos animais a partir de fontes escritas. Analisando quatro diferentes casos (Darwin, os naturalistas, os behavioristas e a sociobiologia), a autora sugere que visões antropomórficas ou mecanomórficas dos animais emergem como efeitos de formas de escrita diferentes. Nessa comparação, as distinções entre ação e comportamento se tornam paradigmáticas dos dois modelos.

O estilo de descrição do comportamento animal de Charles Darwin é analisado, sobretudo, a partir de A Origem das Espécies (2004 [1859]) e A Expressão das Emoções no Homem e nos Animais (2009 [1872]). Segundo a autora, seu estilo é fortemente naturalista. Nesse estilo, o comportamento animal é descrito em termos de uma sucessão de ações que criam eventos em um mundo vivido e experimentado pelos animais, que, para eles, possui um sentido. Suas ações são de sua autoria, e mesmo sugestões, ou inferências, de emoções e raciocínio são efetuadas. Os animais não apenas emergem como autores de suas ações, mas autores intencionais que exercem atividades a que os pesquisadores tentam dar inteligibilidade através do uso de uma linguagem

Caderno Eletrônico de Ciências Sociais, Vitória, v. 3, n. 1, pp. 75-94. 
comum ao mundo humano, não técnica, e a partir de observações e de estudos prévios.

Nesse estilo, diz Crist (1999), a linguagem utilizada guarda três dimensões: a autoria da ação pelo animal, o sentido da ação em um contexto subjetivamente experimentado pelo seu autor e a continuidade temporal das ações no curso da vida. Ancorada numa análise fenomenológica, Crist (1999) sugere que o efeito é representar os animais como sujeitos em termos normalmente utilizados para o universo humano ${ }^{8}$. A subjetividade, afirma a autora, inclui, por sua vez, duas dimensões: o sentido da experiência e da ação e sua autoria ${ }^{9}$. Isso permite acessar, ou sugerir, um ponto de vista animal. Assim, o relato naturalista é acusado de ser antropomórfico, como o foram as descrições efetuadas pelo próprio Darwin.

Quem acusa, por sua vez, está ancorado em um tipo de descrição diferente, cujo efeito é representar os animais como máquinas e objetos, cujo comportamento é pré-determinado por programações inatas. É o caso dos behavioristas. O rompimento com o antropomorfismo se daria através da construção de uma série de categorias técnicas para a descrição das ações dos animais. Como resultado, uma separação entre mente e corpo é alcançada através da descrição. Sem raciocínio e sem mentalidade, os animais não são autores de suas ações, mas organismos, mecanismos ou programas, isto é, autômatos (CRIST, 1999). A necessidade de separação de humanos e animais embasa toda a separação da linguagem utilizada para descrever o mundo

8 Latour (2001, p. 21) afirma que "a fenomenologia trata apenas do mundo-para-umaconsciência-humana" e que "esse conhecimento de nada servirá para a percepção real das coisas [...] [pois] ao invés de investigar as maneiras de passar de um ponto de vista a outro, ficaremos eternamente presos ao ponto de vista dos homens". Nesse sentido, a análise fenomenológica de Crist (1999) acerca da mente animal como ponto relevante da agência animal, conquanto baseada em sua leitura de Darwin, seria considerada antropomórfica visto que a fenomenologia versa sobre os homens, não as coisas. Ela não acessaria, de fato, a mente animal. Cabe ao leitor decidir seguir as percepções latourianas sobre a fenomenologia ou ampliar seu escopo até os animais, na qualidade de não-humanos especiais, dotados de mentes ativas e de um tipo de consciência. Para uma crítica ao antropomorfismo, ver a própria Crist (1999).

9 Dar subjetividade aos animais é um ponto polêmico mesmo entre aqueles que lhes atribuem agência. Para Crist (1999), não há ação sem subjetividade, posto que as duas dimensões que definem esta última também definem a primeira. Albernaz (2013), por exemplo, em um artigo sobre a tauromaquia em Portugal, afirma que os touros possuem agência, mas não subjetividade, pois suas ações decorrem de uma percepção do mundo que é corporal e não intelectual. A essa proposição, Crist (1999, p. 31) responderia que "a própria raison d'être da ação e sua forma sensória não podem ser retiradas da percepção de uma ação como tendo sentido através da experiência". Ela localiza no ceticismo a noção de que não se pode alcançar a mente de outrem além de si mesmo. Deriva dessa ideia a observação do comportamento objetivo dos animais em oposição à sua inobservável vida mental, que portanto passa como se não existisse. Em sua análise de Darwin, contudo, Crist (1999, p. 33, grifo meu) sugere que "ele não especula sobre estados mentais (ou subjetivos) dos animais a partir de expressões comportamentais, mas, de outro modo, testemunha tais estados nas expressões comportamentais". A divisão cartesiana entre mente e corpo que perpassa os escritos behavioristas, portanto, permanece e demonstra o quão complexas podem ser as formas de se atribuir agência aos animais em situações empíricas dadas. 
humano e o mundo animal, como se fossem antitéticos. Se antitéticos, qualquer descrição que construa uma ponte entre humanos e animais em termos de agência se torna antropomórfica. O comportamento animal não é mais uma ação, não é controlado pelo animal, não é de sua autoria nem engendra nenhum tipo de compreensão sua do mundo.

A oposição entre ação e comportamento ${ }^{10}$, segundo ela, foi elaborada nas ciências sociais e behavioristas.

\begin{abstract}
"Brevemente disposto, 'ação' é identificada com uma conduta acompanhada e/ou precedida por estados mentais, enquanto 'comportamento' é concebido como uma conduta física, um produto do corpo, ou uma resposta meramente física originado-se do meio ambiente ou de estímulos internos fisiológicos sem nenhum estado corolário de conhecimento, compreensão, intenção ou sentimento" (CRIST, 1999, p. 210).
\end{abstract}

Nas definições acima, a autora chama a atenção para uma percepção de ação que a equaciona com a soma de um comportamento a estados mentais. A ação se torna humana, ao passo que o comportamento é animal, ancorado numa percepção de que os animais não possuem estados mentais. Os animais se tornam objetos e os humanos sujeitos, permeados por uma agência que decorre do pensamento. A ênfase nos estados mentais envolvidos na ação (humana) são tanto o produto quanto a causa da distinção entre humanos e animais. Sem utilizar o mesmo conceito para atividades que poderiam, de outra forma, ser todas consideradas como "condutas" (se houvesse a possibilidade de uma linguagem neutra), a separação de conceitos reforça e é produto da separação entre os universos humano e animal. A criação de conceitos específicos para falar dessa separação, indica Crist (1999), é um trabalho contínuo de separação do que, de outra forma, poderia ser visto como conjunto. Esse trabalho indica que a separação não é um dado da natureza, mas uma construção.

Se o antropomorfismo é uma forma equivocada de descrição, então o uso de conceitos tecnocientíficos seria uma forma correta. O problema, segundo Crist (1999), é que os termos técnicos não são mais neutros do que os termos antropomórficos e não garantem, necessariamente, um acesso mais objetivo ao universo animal, embora seja isso que pretendam. Nenhuma linguagem, afirma a autora, é ou pode ser neutra ou imparcial.

Para Crist (1999), o antropomorfismo não deve ser visto como uma metáfora ou um erro, mas como uma descrição realista da vida animal, ancorada, conforme as noções do próprio Darwin, em uma teoria de evolução das espécies. Para Darwin (2004 apud CRIST, 1999), não há saltos evolutivos entre humanos e animais (natura non facit saltum), mas uma continuidade que permite perceber, nos animais, características dos humanos que são tidas, portanto, como produto da evolução (CRIST, 1999). Em outras palavras, não são os animais que possuem características humanas, antropomórficas, mas os humanos que desenvolveram, como espécie participante no processo evolutivo

10 Ao longo desse trabalho não se utilizou a ideia de comportamento animal em oposição à ação.

Caderno Eletrônico de Ciências Sociais, Vitória, v. 3, n. 1, pp. 75-94. 
da vida na Terra, características que existem seminalmente em outras espécies, incluindo-se os atributos mentais: imitação, atenção, memória, imaginação e razão, segundo Crist (1999), seriam encontrados nas descrições darwinianas dos animais. Para o pai da teoria da evolução das espécies, a diferença entre os atributos mentais humanos e animais seria de grau e não de tipo. Não obstante, a autora indica que uma visão mecanicista dos animais não é necessariamente incompatível nem com a teoria darwinista da evolução das espécies, nem com uma continuidade mental entre animais e humanos.

Mais ainda, a autora sugere que a própria noção de antropomorfismo, como categoria de acusação, não foi bem utilizada. Etimologicamente, significaria "como os humanos". Se não houver uma prescrição anterior do que seja humano, a categoria não apresenta conteúdo. Desse modo, ela só faz sentido na separação a priori dos universos animal e humano. Assim, o termo é avaliativo e utilizado na crítica a análises e descrições consideradas não científicas, metafóricas, equivocadas, ingênuas e que fazem comparações irrestritas entre humanos e animais, mas também é um efeito de um tipo de descrição que não cria termos especiais para falar dos animais, mas os descreve em termos do universo de atividades humanas.

Por se tratar igualmente de uma narrativa, o campo da história dos animais pode se beneficiar das reflexões de Crist (1999). A preocupação com uma análise antropomorfizada se esvai se uma separação a priori entre humanos e não-humanos não existir. A partir das propostas contemporâneas que levam em consideração os animais reais, parece-me que essa separação não é buscada nem alimentada, embora não se trate de diluir fronteiras, mas de acessar pontos de contato. A tensão entre buscar um animal real ou um animal representado também se esvai, dado que todo animal analisado, descrito e narrado é um animal representado, seja ele real ou imaginário. A materialidade dos animais nessas narrativas, contudo, não precisa se esvair.

A busca por materialidade em fontes etológicas desloca a solução encontrada para a velha tensão entre sujeito e objeto. Dependendo da fonte, a descrição behaviorista ou naturalista apontará animais cujas condutas e comportamentos são explicados e descritos em termos diferentes. Em outras palavras, a etologia não apresenta um conteúdo neutro que embase a materialidade do animal e é, portanto, uma fonte escrita como outras, cujo bias deve ser levado em consideração. Nesse sentido, as descrições naturalistas parecem muito mais interessantes a quem busca a agência animal do que as behavioristas ou sociobiológicas (CRIST, 1999; DESPRET, 2010). Igualmente, Despret (2008) apontou, sobre as descrições do comportamento dos primatas, que estas seguem ideias e valores de cada época, mudando ao longo do tempo. Não estaríamos, nesse sentido, fazendo o mesmo? A nova centralidade do naturalismo nos animal studies não seria devedora direta de uma agenda político-ideológica?

Levar em consideração um bias criado por uma narrativa ou prática científica não significa, no entanto, que a produção científica não tenha nada a nos dizer sobre a realidade. Como aponta Haraway (1991), múltiplos fatores interferem nas opções teóricas e metodológicas de um pesquisador, e na própria criação de teorias e metodologias. Não se perde de vista, contudo, a diferenciação entre uma ciência bem-feita e uma ciência malfeita. Conforme 
Latour (2000b), toda ciência apresenta um bias e se isso invalidar toda a possível apreensão científica da realidade, não haveria por que fazer ciência. 0 que Crist (1999) analisa não é a incapacidade da ciência de acessar a realidade, mas as imagens produzidas por distintas formas científicas de analisar e descrever uma mesma realidade.

\section{Considerações finais}

Baker (1993) sugere que toda a relação que travamos com os animais está perpassada por aspectos simbólicos, portanto não haveria como analisar o animal real se ele é também uma representação. Embora o início da sentença seja válido, o seu final é obtuso, pois parece demandar uma purificação, nos termos de Latour (1994), entre realidade e imaginário, natureza e cultura. O que é um animal real, afinal? Se os animais que povoam nosso cotidiano não fossem reais, não teríamos vacinas antirrábicas, repelentes de mosquitos, venenos para ratos e baratas, rações e uma série de produtos em pet shops e lojas agropecuárias, legislação protetiva, criações para abate, etc. Se as narrativas representam animais de alguma forma, isto não significa que eles não sejam reais. Captar o animal real numa narrativa é como captar humanos reais: eles se engajam em atividades.

A dicotomia entre real e representado, na história dos animais, parece dar lugar a formas de se pensar o animal que rompem tanto com as visões mecanicistas de seres autômatos, como com sua visão de seres naturais apartados da ordem humana e social. A noção de agência, em que pese suas múltiplas definições, contribui para a percepção dos animais como seres com os quais interagimos e que povoam nosso mundo real e imaginário, nossas vidas e, talvez, nossas mortes.

Participantes de naturezas-culturas, os humanos e os animais, junto a outros não-humanos, habitam um mundo compartilhado, embora os significados atribuídos por cada um a esse mundo não sejam necessariamente os mesmos. Sem pretender acessar a mente ou a perspectiva animal, a história dos animais parece tentar se afastar da cômoda zona do estudo das representações humanas sobre os animais para ingressar no turbulento território em construção dos animais como agentes subjetivos, sensórios e que dão significando ao seu mundo. Essa guinada ao concreto parece ser tanto uma incorporação de questões pertinentes aos science studies, especialmente na incorporação dos objetos às análises, quanto de questões relativas à etologia naturalista, que tem ganhado expressão como fonte para parte da produção recente da história dos animais.

Contudo, há que se observar esse movimento. Se reconhecer a existência material dos animais é uma contribuição significativa para uma história dos animais que se propõe ser análoga à história social e sua visão moldada a partir do plano do humano comum, acessar essa materialidade a partir de fontes científicas pode criar um risco de se reiterar uma divisão entre ciências naturais e humanas (ou sociais) e os animais como seres naturais. Afinal, os cientistas não são os únicos a acessar a materialidade animal, nem os únicos a formular teorias sobre o comportamento animal. É reconhecido que treinadores, criadores e cuidadores de animais também criam explicações para o 
comportamento das espécies com as quais convivem. Creio que haverá novos estados da arte em breve, pois o campo tem demonstrado um dinamismo instigante.

\section{Referências bibliográficas:}

ALBERNAZ, L. S. 2013. Festa brava portuguesa: pessoas humanas e pessoas animais. Revista Anthropológicas, Recife, ano 17, v. 24, n. 1, p. 181-203.

APROBATO FILHO, N. 2006. O couro e o aço: sob a mira do moderno: a 'aventura' dos animais pelos 'jardins' da Paulicéia, final do século XIX/início do século XX. São Paulo. Tese em História Social, USP.

BAKER, S. 1993. Picturing the beast: animals, identity and representation. Champaign: University of Illinois Press.

BIRKE, L. 2002. Intimate familiarities? Feminism and human-animal studies. Society and Animals, Leiden, v. 10, n. 4, p. 429-436.

CRIST, E. 1999. Images of animals - anthropomorphism and animal mind. Philadelphia: Temple University Press.

CROSBY, A. W. 2011. Imperialismo ecológico: a expansão biológica da Europa, 900-1900. São Paulo: Cia. das Letras.

DARNTON, R. 1986. Os trabalhadores se revoltam: o grande massacre de gatos na Rua Saint-Séverin. In: DARNTON, Robert. O grande massacre de gatos e outros episódios da história cultural francesa. Rio de Janeiro: Graal. p. 103-39.

DARWIN, C. 2004. A origem das espécies. São Paulo: Martin-Claret.

DARWIN, C. 2009. A expressão das emoções no homem e nos animais. São Paulo: Cia. de Bolso.

DELORT, R. 1984. Les animaux ont une histoire. Paris: Seuil.

DESPRET, V. 2008. Culture and gender do not dissolve into how scientists 'read' nature: Thelma Rowell's Heterodoxy. In: HARTAMAN, O.; FRIEDRICH, M. (eds.). Rebels of life: iconoclastic biologists in the twentieth century. New Haven: Yale University Press. p. 340-355.

DESPRET, V. 2010. Ethology between empathy, standpoint and perspectivism: the case of the arabian babblers. Disponível em: <www.vincianedespret.be/2010/04/ethology-between-empathystandpoint-and-perspectivism-the-case-of-the-arabian-babblers/> Acesso em: 01 de mar. 2015.

DESPRET, V. 2013. From secret agents to interagency. History and Theory, Middletown, $v$. 52, dez. Disponível em: $<$ www.vincianedespret.be/papers/from-secret-agents-to-interagency/> Acesso em: 01 de mar. 2015.

DUARTE, R. H. 2013. Birds and scientists in Brazil: in search of protection, 1894-1938. In: FEW, M.; TORTORICI, Z. (eds.). Centering animals in latin american history. Durham: Duke University Press. p. 270-301.

FEW, M.; TORTORICI, Z. 2013. Centering animals in latin american history. Durham: Duke University Press.

FUDGE, E. 2002. A left-handed blow: writing the history of animal. In: ROTHFELS, N. (ed.). Representing animals. Bloomington: Indiana University Press, p. 3-18. 
FUDGE, E. 2014. What was it like to be a cow? History and animal studies. In: KALOF, L. (ed.). The oxford handbook of animal studies. Oxford: Oxford, 2015 (no prelo). Disponível em: $<w w w . a c a d e m i a . e d u / 10531292 /$ What_was_it_like_to_be_a_Cow_History_ and_Animal_Studies> Acesso em: 15 fev. 2015.

GOLDMAN̄, Márcio. 1999. Lévi-Strauss e os sentidos da História. Revista de Antropologia, v. 42, n.1-2, p. 223-238. Disponível em <http://www.scielo.br/scielo.php?script=sci_arttext\&pid=S0034-

$77011999000100012 \& \mathrm{lng}=$ pt\&nrm=iso $>$. Acesso em 20 mar. 2009.

HARAWAY, D. 1991. Simians, cyborgs, and women: the reinvention of nature. New York: Routlegde.

HRIBAL, J. C. 2007. Animals, agency, and class: writing the history of animals from below. Human Ecology Review, s/l, v. 14, n. 1, p. 101-112.

HYAMS, E. 1972. Animals in the service of man: 10.000 years of domestication. London: J. M. Dent \& Sons.

INGOLD, T. 2000.The perception of environment: essays on livelihood, dwelling and skill. London: Routledge.

KEAN, H. 1998. Animal rights: political and social change in Britain since 1800. London: Reaktion.

KRUSE, C. R. 2002. Social animals: animal studies and sociology. Society and Animals, Leiden, v. 10, n. 4, p. 375-379.

LANSBURY, C. 1994. The old brown dog: women, workers and vivisection in edwardian England. Madison: The University of Wisconsin Press, 1985.

LATOUR, B. 1994. Jamais fomos modernos: ensaio de antropologia simétrica. Rio de Janeiro: Ed. 34.

LATOUR, B. 2000a. Ciência em ação: como seguir cientistas e engenheiros sociedade afora. São Paulo: Ed. UNESP.

LATOUR, B. 2000b. A well-articulated primatology: reflexions of a fellowtraveller. In: SRUM, S.; FEDIGAN, L. (eds.). Primate encounters. Chicago: University of Chicago Press, p. 358-381.

LATOUR, B. 2001. A esperança de pandora: ensaios sobre a realidade dos estudos científicos. Bauru: EDUSC.

LÉVI-STRAUSS, C. 2008. O pensamento selvagem. Campinas: Papirus, 9 ed.

MARX, K. 2011. O 18 brumário de Luís Bonaparte. São Paulo: Boitempo.

MULLIN, M. 2002. Animals and anthropology. Society and Animals, Leiden, v. 10, n. 4, p. 387-393.

NANCE, S. 2013. Entertaining elephants: animal agency and the business of the American circus. Baltimore: Johns Hopkins University Press.

NOSKE, B. 1993. The animal question in Anthropology: a commentary. Society and Animals, Leiden, v. 1, n. 2. p.185-190.

PASTOUREAU, M. 2010. L'historien face à I'animal: I'exemple du Moyen Age. In: BIRNBAUM, J. Qui sont les animaux? Paris: Gallimard, p. 194-209.

PREMACK, D; PREMACK, A. J. 1994. Why animals have neither culture nor history. In: INGOLD, T. (ed.). Companion encyclopedia of anthropology. London: Rutledge, p. 350-365.

RITVO, H. 1987. The animal state: the English and other creatures in the victorian age. Cambridge: Harvard University Press. 
RITVO, H. 2002. History and animal studies. Society and Animals, Leiden, v. 10, n. 4, p. 403-406.

THOMAS, K. 1988. O homem e o mundo natural: mudanças de atitude em relação às plantas e aos animais (1500-1800). São Paulo: Cia. Das Letras.

WALKER, B. L. 2005. The lost wolves of Japan. London: University of Washington Press. 